Current Practice

\title{
Living with biliary atresia: From Kasai portoenterostomy to liver transplantation
}

\author{
*Naresh P Shanmugam ${ }^{1}$, Gomathy Narasimhan ${ }^{2}$, Shaman Rajindrajith ${ }^{3}$ \\ Sri Lanka Journal of Child Health, 2016; 45(2):116-122 \\ DOI: http://dx.doi.org/10.4038/sljch.v45i2.8116 \\ (Key words: Biliary atresia, Kasai portoenterostomy, liver transplantation)
}

\section{Introduction}

Biliary atresia (BA) is a neonatal disease of unknown aetiology causing obstruction of the biliary system resulting in jaundice and progressive liver failure. It would lead to death, if untreated. The reported incidence varies from 1 in 10,000 to 1 in 20,000 births. Kasai portoenterostomy (KPE), where a loop of small intestine is attached to the hilum of the liver after dissecting the portal plate can help in establishing bile flow. But unfortunately, KPE is not curative surgery and the majority of patients would require liver transplantation (LT) before reaching adulthood. Although the exact prevalence is not known, a sizeable number of infants are born in Sri Lanka with BA and most of them undergo KPE. However, Sri Lanka currently lacks facilities for LT and most BA end up with chronic liver disease (CLD) and sufferers succumb to complications. The management of children with post-Kasai complications is challenging and paediatricians must have an up-to-date knowledge on early recognition, appropriate investigation and effective therapeutic interventions. This article deals with the expected long term complications in children with BA and would help paediatricians to anticipate and manage them successfully.

Professor Morio Kasai operated on a 72-day old infant with BA in 1955, where he placed a loop of duodenum over the dissected hilum of liver to achieve haemostasis. Postoperatively, the baby passed yellow stools and cleared jaundice ${ }^{1}$. This surgery, popularly known as KPE has become the

${ }^{1}$ Department of Paediatric Gastroenterology, Hepatology and Transplantation, Global Health City, Chennai, India, ${ }^{2}$ Institute of liver diseases and Transplantation, Global Health City, Chennai, India, ${ }^{3}$ Department of Paediatrics, Faculty of Medicine, University of Kelaniya, Sri Lanka

*Correspondence: drnareshps@gmail.com

The authors declare that there are no conflicts of interest

Personal funding was used in formulating the article.

Open Access Article published under the Creative

Commons Attribution CC-BY (cc) License. standard treatment for all children with BA diagnosed early. KPE has undergone several modifications with extensive dissection of the portal plate at the hilum so that biliary ductules are exposed and a $60 \mathrm{~cm}$ Roux-en-Y loop of jejunum is attached to facilitate bile flow into intestine ${ }^{2}$. KPE provided new hope to children with BA, as these children did not survive beyond 24 to 36 months of age if untreated ${ }^{3}$. Unfortunately, not all children with BA who have undergone KPE would clear jaundice. Over the years, several factors were evaluated as prognostic markers of successful KPE. It was found that late diagnosis and delayed surgery, presence of associated anomalies such as Biliary Atresia Splenic Malformation (BASM), laparoscopic portoenterostomy, failure to clear jaundice in three months after surgery and repeated cholangitis were associated with adverse outcome ${ }^{4}$.

The age at which KPE is performed has an effect on native liver survival (NLS). Many series have shown that jaundice clearance rate correlated well with early KPE and suggested cut off value for offering KPE is below 90 days of birth ${ }^{5}$. Decision for late KPE (>90days) has to be taken on an individual case basis. Presence of ascites and synthetic liver failure such as prolonged international normalised ratio (INR) and low albumin are indicators of advanced liver disease, where KPE should not be offered. Surgical expertise plays an important role and it was shown that better jaundice clearance was achieved by surgeons who perform five or more KPE per year and it is one of the important reasons for limiting KPE to three centres in the whole of the United Kingdom ${ }^{6}$. Presence of associated anomalies such as polysplenia, gut malrotation, situs inversus and pre-duodenal portal vein, point towards poor outcome after KPE.

\section{Missed Kasai portoenterostomy}

Children who do not undergo KPE usually do not survive beyond 24 to 36 months of age, if they are not transplanted. These children usually do well during the first six months of life with normal somatic growth and no external manifestations of liver failure apart from jaundice. After this period, their growth falters and they start to develop 
external manifestations of CLD like ascites, oedema etc., and ultimately succumb. Timing of LT is crucial in these children and it has to be done during early liver decompensation and the time gained by this waiting period should be utilised to optimise vaccination and nutrition. In our experience, the ideal time to perform LT in children who have missed KPE would be around nine months, beyond which the complications of liver failure would start to manifest. At around nine months the child would be more than $6 \mathrm{~kg}$ and has adequate abdominal cavity space to accommodate donor liver and moreover, would have completed primary vaccinations. In developing countries where LT facilities are sparse, it is advisable for the infants with missed KPE to be reviewed and counselled in centres with LT facilities at the earliest. This will help the parents to understand the logistics involved in LT, such as choosing the donor and their financial commitments.

Natural history after KPE

As a rule of thumb, one-third of children who had $\mathrm{KPE}$ at an appropriate age will not clear jaundice (failed KPE), another one-third would clear jaundice but would get back jaundice in early childhood following disease progression/ cholangitis requiring LT. The remaining one-third would clear jaundice and remain jaundice free until they enter adulthood ${ }^{7}$.

Successful KPE: Those who clear jaundice and pass pigmented stools are considered as successful KPE. Biochemically, serum bilirubin levels should fall below $2 \mathrm{mg} / \mathrm{dl}$ within 3 months of $\mathrm{KPE}^{2}$. Successful KPE does not mean a perfectly normal liver and safe transition to adulthood. These children can have raised transaminase and continue to have liver fibrosis and can develop secondary complications such as portal hypertension (PHT), variceal bleed, growth failure, ascites, hepatopulmonary syndrome (HPS) etc., without jaundice, necessitating LT. Approximately half of successful KPE would develop complications mentioned in figure 1, necessitating LT before adulthood. Recurrent cholangitis is an important risk factor for jaundice recurrence and subsequent need for LT.

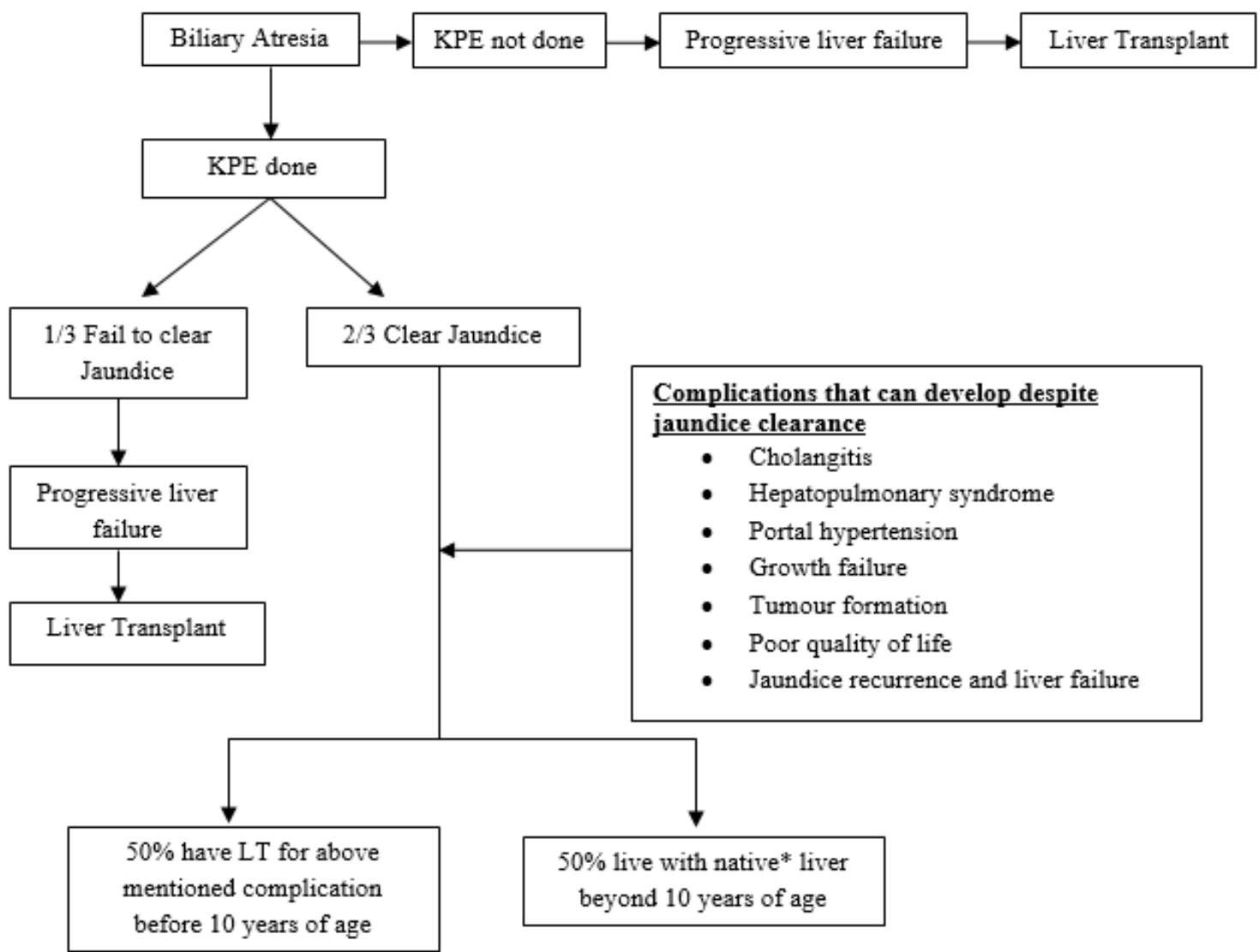

Figure 1: Schematic diagram showing approach to management of biliary atresia

*can have the above mentioned complications to variable extent but not warranting transplant 
Failed KPE: Failure to establish bile flow after $\mathrm{KPE}$ is considered as failed KPE and it is measured in terms of persistently elevated serum bilirubin levels beyond three months of KPE. The natural course of failed KPE would be similar to children who did not have KPE. Transplantation has to be considered when the child starts developing liver failure such as low albumin, prolonged INR etc., or complications such as cholangitis, HPS etc., develop. Transplantation should be offered at around 9 to 12 months and much earlier if they develop complications of CLD.

\section{Complications of BA}

Children who did not undergo KPE and those who have failed KPE have a predictable course of illness. They gradually develop complications related to liver failure and cirrhosis such as low albumin, coagulopathy, PHT etc., and ultimately succumb if not transplanted. Children who had successful KPE should be kept under constant surveillance to monitor their growth and for occurrence of any secondary complications.

Cholangitis: Ascending cholangitis can happen at any time from KPE surgery to several years after successfully clearing jaundice. It has been quoted that $40-60 \%$ of children who have undergone KPE will get cholangitis. Cholangitis has to be suspected in children who have undergone KPE when they present with high-grade fever and raised inflammatory markers such as C-reactive protein (CRP) along with raised liver enzymes. Usually there will be a history of acholic stools during these episodes. Cholangitis could be fatal if not treated properly with intravenous antibiotics and is the most common cause for recurrence of jaundice in children with successful KPE. Sometimes they might develop into liver abscess, which would require drainage. Frequent episodes of cholangitis are associated with a shorter native liver survival (NLS). Recurrent cholangitis is an indication for LT. Prophylactic cyclical antibiotics can help in preventing repeated episodes of cholangitis.

Portal hypertension: The normal pressure of the portal venous system is $5-10 \mathrm{~mm} \mathrm{Hg}$ and pressures greater than $10 \mathrm{~mm} \mathrm{Hg}$ is considered as PHT. Bridging fibrosis is seen on histology in almost half the patients at the time of $\mathrm{KPE}^{8}$. Despite being a successful KPE, fibrosis can progress and the child can develop severe PHT and secondary complications such as variceal bleed, ascites and HPS due to it. Fibrosis and jaundice clearance do not have a correlation. PHT causes congestion of splanchnic venous circulation resulting in intestinal mucosal oedema and protein loss, contributing towards malnutrition in these children. Variceal bleeding is a common complication of PHT. The most common sites of varices are the oesophagus, the stomach, the jejunal site of the Roux loop anastomosis, and the anorectum. Around 20\% of successful KPE children who did not require LT had variceal bleeding in the first two years of life ${ }^{9}$. This highlights the need for surveillance endoscopy in children with successful KPE. Variceal haemorrhage carries a low risk of death in children with no parenchymal liver disease such as portal vein thrombosis, while mortality is high in cirrhotic patients such as BA since cirrhosis causes an increased hepatic artery resistance index (HARI). Difference in peak systolic velocity and diastolic velocity divided by peak systolic velocity provides the resistive index, which could be measured using the Doppler ultrasound. As the pressure required to perfuse cirrhotic liver is high, there is relative organ (liver) specific hypoxia during acute bleeding as hypotension leads to decreased perfusion of the liver. This insult can cause sudden deterioration of liver function and can progress to liver failure in otherwise stable children.

Unlike adults, there is no randomised controlled trial (RCT) data to support the use of prophylactic non-selective beta-blockers such as propranolol to decrease the risk of variceal bleed. In adults, the drug dose is titrated to decrease the resting heart rate by $25 \%$ which would correspond to a decrease in portal venous pressure. In children, there is a practical difficulty in drug dosing as heart rate varies with age and it is difficult to assess the baseline heart rate $^{9}$. Children are more dependent upon chronotropy for maintenance of systemic blood pressure during hypovolaemia and betablockers would prevent a tachycardiac response. Published experience from case series has shown that propranolol could be safely used for primary prophylaxis, but the benefit attributed to it is not known. In children, there is no recommendation on surveillance endoscopy and endoscopic variceal ligation (EVL) / endoscopic sclerotherapy (EST) as primary prophylaxis.

In successful KPE with good liver synthetic function, if the only problem is PHT and variceal bleed, shunt surgery could be considered. In case of an actual bleed, child has to be resuscitated appropriately using fluids and blood products, octreotide infusion has to be started and then the child shifted to a higher centre for endoscopy. Caution should be exercised during transfusion to keep haemoglobin below $9 \mathrm{~g} / \mathrm{dl}$, as hypervolaemia can cause a re-bleed. The majority will stop bleeding with medical management. Occasionally, bleeding from gastric varices and Roux en Y jejunal loop varices might be difficult to control and require interventional measures such as transjugular intrahepatic portosystemic shunt (TIPSS), surgical shunts, esophagogastric devascularisation + splenectomy $^{10}$. LT has to be 
offered to those with CLD after control of the acute bleeding episode.

Ascites: Low albumin in CLD results in accumulation of fluid in the extravascular space leading to oedema, ascites and pleural effusion. PHT also contributes towards formation of ascites. Presence of ascites is one of the variables that increase the mortality in children with $\mathrm{CLD}^{11}$. Onset of ascites indicates decompensation of liver disease and the need for LT. Ascites increases the risk of bacterial peritonitis and hepatorenal syndrome, which potentially adds to the already increased mortality associated with liver decompensation. Apart from the above-mentioned two complications, ascites decreases the mobility of the patient and causes respiratory distress, potentially affecting the quality of life (Figure 2).

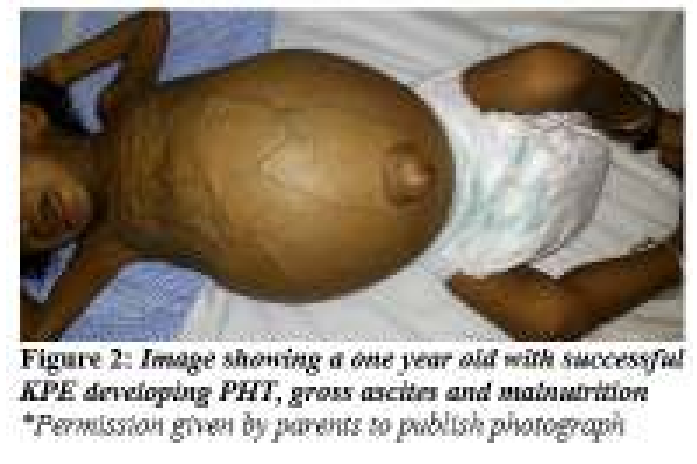

Diuretic therapy remains the first line of treatment in ascites. Spironolactone (aldosterone antagonist), is the initial drug of choice, started at $3 \mathrm{mg} / \mathrm{kg} / \mathrm{day}$ in 3 or 4 divided doses and gradually increased to 6 $\mathrm{mg} / \mathrm{kg} /$ day (maximum dose $400 \mathrm{mg} /$ day). Potent loop diuretics such as frusemide $(1-2 \mathrm{mg} / \mathrm{kg}$ ) could be added if there is no effective diuresis on monotherapy. Spironolactone causes hyperkalaemia while frusemide causes hyponatraemia and hypokalaemia, which have to be monitored regularly. Sometimes, dual therapy with these drugs is beneficial as potassium loss by frusemide is countered by potassium conservation by spironolactone. The suggested optimal drug dosage ratio to achieve this is 2 frusemide: 5 spironolactone. Tolvaptan is an oral vasopressin receptor antagonist that helps in free water excretion and corrects hyponatraemia, and has been approved by US Food and Drug Administration (FDA) for use in adults with cirrhosis. It is currently under phase three trials for its safety in children. Paracentesis is indicated in case of tense ascites causing respiratory distress. Usually $20 \%$ albumin at a dose of $5 \mathrm{ml} / \mathrm{kg}$ is given slowly over two hours during the procedure as a plasma expander as well as to prevent rapid reaccumulation of ascites
Pulmonary complications in cirrhosis: The common pulmonary complications of CLD are HPS, portopulmonary hypertension and pulmonary hydrothorax. HPS is common after KPE irrespective of jaundice clearance. The diagnostic criteria for HPS are the presence of CLD, along with $\mathrm{PaO}_{2}$ less than $70 \mathrm{~mm} \mathrm{Hg}$ or alveolar-arterial oxygen gradient more than $15 \mathrm{~mm} \mathrm{Hg}$ and intrapulmonary vascular dilatation ${ }^{12}$. The overall prevalence of HPS ranges from 4 to $30 \%$ in cirrhotics. Prevalence of HPS in the paediatric population with CLD is around 8 to $20 \%{ }^{13,14}$. Good clinical examination, looking for clubbing, cyanosis, spider naevi and checking saturation once in six months will help to diagnose HPS early, as transplant would be contraindicated in late stages where $\mathrm{PaO}_{2}$ remains less than $50 \mathrm{~mm} \mathrm{Hg}$ despite administering $100 \%$ oxygen via face mask.

Failure to thrive: Poor somatic growth is common in BA and it is an important variable that is associated with increased post-transplant mortality and morbidity ${ }^{15}$. Nutritional requirement is increased in CLD due to increased resting energy expenditure (REE) and total energy expenditure (TEE). But there is a relative deficiency of food intake as a large proportion of fat is excreted unabsorbed due to the absence of bile salts, along with decreased intake due to early satiety, nausea and vomiting. Drugs that are used to decrease bile acid pools such as cholestyramine, interfere with fat-soluble vitamin absorption. Caution should be exercised while performing anthropometry in these children, as ascites and large spleens will contribute to weight and give a false sense of good somatic growth. Mid-arm muscle circumference and skin fold thickness are fairly reliable indicators of nutritional status as upper arm is less likely to be affected with oedema.

Nutritional management of infants who failed to clear jaundice is aimed at gaining weight and muscle mass, so that the morbidity during transplantation could be minimised. Nasogastric feeds have to be considered if adequate calorie intake could not be achieved by oral intake. Table 1 shows the outline of nutritional management of children with liver disease. Failure to thrive, despite adequate nutritional rehabilitation is an indication for LT regardless of successful or failed KPE.

Other complications: Intense pruritus, poor school attendance, low grade encephalopathy etc. affect the quality of life. A poor quality of life is an indication for LT. Hepatocellular carcinoma (HCC) is a well-known complication in BA. Diagnosis of HCC might be difficult in a cirrhotic liver with regenerating nodules and if there is a high degree of suspicion LT should be offered. 
Table 1: Nutritional management of children with liver disease

Caloric intake: $130-180 \mathrm{kcal}(545-750 \mathrm{~kJ}) / \mathrm{kg} /$ day for infants and $120-150 \%$ EAR for age in children

Protein: Infants to be supplemented with 3-4 g/ $\mathrm{kg} / \mathrm{day}$ and children with $2 \mathrm{~g} / \mathrm{kg} / \mathrm{day}$ of proteins. Protein intake to be limited to the recommended daily allowance (RDA), if there is encephalopathy.

Fat and carbohydrate: Carbohydrates to account for 40 to $60 \%$ of caloric intake and rest as fat. MCT oil can be supplemented separately in a total daily dose of $1-2 \mathrm{ml} / \mathrm{kg} /$ day in $2-4$ doses

Vitamin A: Water soluble vitamin A preparation is recommended at a dose of $5000-10,000 /$ day. Serum retinol $<20 \mathrm{mcg} / \mathrm{dl}$ or Retinol-Retinol binding protein molar ratio $<0.8$ indicates deficiency.

Vitamin D: Ergocalciferol (vitamin D2): 3-10 times the RDA for that age group; cholecalciferol (vitamin D3): 50 to 100 units $/ \mathrm{kg} /$ day; $1-25$-dihydroxy vitamin D: $0.05-0.20 \mathrm{mcg} / \mathrm{kg} /$ day (severe resistant cases)

Vitamin E: $\alpha$-Tocopherol : 25-50 IU/kg/day; Tocopherol polyethylene glycol-succinate (TPGS): 15-25 $\mathrm{IU} / \mathrm{kg} / \mathrm{day}$

Vitamin K: $2.5-5 \mathrm{mg}, 2-7$ times/week

Water-soluble vitamins: Angular cheilitis, stomatitis, glossitis etc. are some of the manifestation of water soluble vitamin deficiencies. In case of deficiency, multivitamin preparation providing at least $100 \%$ of RDA for that age group.

Trace Elements and mineral deficiency: Deficiency of iron, zinc, selenium, magnesium were common in children with $\mathrm{CLD}^{16}$. If plasma zinc concentration is $<60 \mathrm{mcg} / \mathrm{dl}$, supplementation with $1 \mathrm{mg} / \mathrm{kg} / \mathrm{day}$ elemental zinc recommended ${ }^{17}$. The diet should meet daily requirement of selenium $(1-2 \mu \mathrm{g} / \mathrm{kg} / \mathrm{day})$, calcium $(50-100 \mathrm{mg} / \mathrm{kg} / \mathrm{day})$ and phosphate $(20-50 \mathrm{mg} / \mathrm{kg} / \mathrm{day})$, otherwise has to be supplemented. Microcytic anaemia with low iron level and increased total iron-binding capacity (TIBC) indicate iron deficiency. Elemental iron at $5-6 \mathrm{mg} / \mathrm{kg} /$ day should be supplemented.

\section{KPE Vs Primary LT for BA}

With the majority of children requiring LT and the morbidity associated with KPE, the usual thought process is whether we could offer primary LT for $\mathrm{BA}$, instead of KPE and then a LT. It is well documented that if KPE is done at the right age by an experienced surgeon, 60 to $70 \%$ of infants would clear jaundice and around $20 \%$ of them would grow past 20 years of age with their native liver ${ }^{18}$. This gives a window of opportunity to immunize these children and make them grow, as liver transplantation done at an older age is associated with fewer complications. In general, infants with BA of more than 120 days should be offered primary LT. Between the ages of 90 to 120 days, KPE has to be individualised. Any child with BA who has developed coagulopathy not corrected by parenteral vitamin $\mathrm{K}$, hypoalbuminaemia and signs of portal hypertension such as significant ascites, should undergo primary $\mathrm{LT}^{3}$.

\section{Timing of liver transplantation}

In developed countries such as the United States where LT is mainly from cadaver donors, it is offered based on paediatric end stage liver disease (PELD) score. The limitations of the PELD score is that it does not take into consideration complications such as cholangitis, severe portal hypertension, pulmonary hypertension and HPS, and could underestimate the risk of death ${ }^{19}$. In developing countries where LT is mainly from living donors, an aggressive, pre-emptive approach to LT is justified, as mortality and morbidity are much less when LT is performed in stable patients in a controlled endeavour. With technical excellence, LT is feasible even on newborn babies but the morbidity and hospital stay are significantly more when compared to children ${ }^{3,20}$. The main problems would be a small abdominal cavity size to accommodate the donor liver, smaller blood vessels where anastomosis would be technically difficult and challenging postoperative intensive care requirements. Timing of LT has to be individualized in BA; it should be neither too early, where it would be technically challenging, nor too late where complications associated with liver failure would increase the mortality and morbidity. Missed BA and failed KPE should be offered LT at around nine months of age while the successful KPE should be carefully monitored and when they develop complications mentioned in the Figure 1, should be transplanted. 
Complications such as intestinal perforations during LT are reported in $4-20 \%$ of children, particularly in those who underwent KPE. These are due to previous adhesions. Portal venous thrombosis is high in BA and has been reported in $6-14 \%$ of cases as hypoplastic portal vein associated with BA poses a risk for increased thrombosis. In spite of these complications, longterm outcome after LT in BA is excellent with ten year patient and graft survival of 85 to $90 \%$ and 75 to $82 \%$, respectively.

To conclude, KPE is a palliative form of surgery and should be offered to all appropriate infants with BA. Early screening and centralization of KPE would result in better outcomes. Parents need to be sensitized about LT, as these children would need it at some point in time. Nutritional support and regular surveillance will enable us to identify complications earlier and offer transplantation at the appropriate time

\section{References}

1. Garcia AV, Cowles RA, Kato T, Hardy MA. Morio Kasai: a remarkable impact beyond the Kasai procedure. Pediatric Surgery 2012; 47(5):1023-7. http://dx.doi.org/10.1016/j.jpedsurg.2012. 01.065

PMid: 22595595 PMCid: PMC3356564

2. Ramachandran P, Safwan M, Reddy MS, Rela M. Recent trends in the diagnosis and management of biliary atresia in developing countries. Indian Pediatrics 2015; 52(10): 871-9. http://dx.doi.org/10.1007/s13312-0150735-6

PMid: 26499012

3. Shneider BL, Mazariegos GV. Biliary atresia: a transplant perspective. Liver Transplantation 2007; 13(11): 1482-95. http://dx.doi.org/10.1002/lt.21303

PMid: 17969203

4. Chung PH, Wong KK, Tam PK. Predictors for failure after Kasai operation. Journal of Pediatric Surgery 2015. 50(2): 293-6. http://dx.doi.org/10.1016/j.jpedsurg.2014.

11.015

PMid: 25638622

5. Chardot C, Carton M, Spire-Bendelac N, Le Pommelet C, Golmard J, Reding R, et al. Is the Kasai operation still indicated in children older than 3 months diagnosed with biliary atresia? Journal of Pediatrics 2001; 138(2): 224-8.

http://dx.doi.org/10.1067/mpd.2001.11127

6

PMid: 11174620

6. Kelly DA, Davenport M. Current management of biliary atresia. Archives of Disease in Childhood 2007; 92(12):11325. http://dx.doi.org/10.1136/adc.2006.10145 1

PMid: 17878208 PMCid: PMC2066090

7. Sinha CK, Davenport M. Biliary atresia. Journal of Indian Association of Pediatric Surgeons 2008; 13(2): 49-56. http://dx.doi.org/10.4103/09719261.43015

PMid: 20011467 PMCid: PMC2788439

8. Wildhaber BE, Coran AG, Drongowski RA, Hirschi RB, Geiger JD, Lelli JL, et al. The Kasai portoenterostomy for biliary atresia: A review of a 27-year experience with 81 patients. Journal of Pediatric Surgery 2003. 38(10): 1480-5. http://dx.doi.org/10.1016/S00223468(03)00499-8

9. Ling SC, Walters T, McKieman PJ, Schwarz KB, Garcia-Tsao G, Schneider BL. Primary prophylaxis of variceal hemorrhage in children with portal hypertension: a framework for future research. Journal of Pediatric Gastroenterology and Nutrition 2011; 52(3): 254-61.

http://dx.doi.org/10.1097/MPG.0b013e318 205993a

PMid: 21336158 PMCid: PMC3728696

10. Rezende-Neto JB, Petroianu A, Santana SK. Subtotal splenectomy and central splenorenal shunt for treatment of bleeding from Roux en $\mathrm{Y}$ jejunal loop varices secondary to portal hypertension. Digestive Diseases and Sciences 2008. 53(2): 539-43.

http://dx.doi.org/10.1007/s10620-007-

9878-1

PMid: 17597406

11. Pugliese R, Fonseca EA, Porta G, Danesi V, Guimaraes T, Porta A, et al. Ascites and serum sodium are markers of increased waiting list mortality in children with chronic liver failure. Hepatology 2014;59(5):1964-71. 
http://dx.doi.org/10.1002/hep.26776

PMid: 24122953

12. Abrams GA, Nanda NC, Dubovsky EV, Krowka MJ, Fallon MB. Use of macroaggregated albumin lung perfusion scan to diagnose hepatopulmonary syndrome: a new approach. Gastroenterology 1998; 114(2): 305-10. http://dx.doi.org/10.1016/S00165085(98)70481-0

13. Sasaki T, Hasegawa T, Kimura T, Okada A, Mushiake S, Matsushita T. Development of intrapulmonary arteriovenous shunting in postoperative biliary atresia: evaluation by contrastenhanced echocardiography. Journal of Pediatric Surgery 2000. 35(11): 1647-50. http://dx.doi.org/10.1053/jpsu.2000.18343 PMid: 11083444

14. Noli K, Solomon M, Golding F, Charron M, Ling SC. Prevalence of hepatopulmonary syndrome in children. Pediatrics 2008; 121(3): e522-7. http://dx.doi.org/10.1542/peds.2007-1075 PMid: 18310172

15. DeRusso PA, Ye W, Shepherd R, Haber BA, Shneider BL, Whitington PF, et al. Growth failure and outcomes in infants with biliary atresia: a report from the Biliary Atresia Research Consortium. Hepatology 2007; 46(5):1632-8. http://dx.doi.org/10.1002/hep.21923 PMid: 17929308 PMCid: PMC3881187

16. Chin SE, Shepherd RW, Thomas BJ, Cleghorn GJ, Patrick MK, Wilcox JA et al. The nature of malnutrition in children with end-stage liver disease awaiting orthotopic liver transplantation. American
Journal of Clinical Nutrition 1992; 56(1):

164-8.

PMid: 1609754

17. Feranchak A, Sokol R. Medical and nutritional management of cholestasis in infants and children. In: Suchy FJ, Sokol RJ, Balistreri WF, editors. Liver Disease in Children $3^{\text {rd }}$ ed. NewYork: Cambridge University Press; 2007. p190-231.

http://dx.doi.org/10.1017/cbo9780511547 409.012

18. Lykavieris $\mathrm{P}$, Chardot C, Sokhn M, Gauthier F, Valayer J, Bernard O. Outcome in adulthood of biliary atresia: a study of 63 patients who survived for over 20 years with their native liver. Hepatology 2005; 41(2): 366-71. http://dx.doi.org/10.1002/hep.20547 PMid: 15660386

19. Shneider BL, Neimark E, Frankenberg T, Arnott L, Suchy FJ, Emre S. Critical analysis of the paediatric end-stage liver disease scoring system: a single centre experience. Liver Transplantation 2005; 11(7): 788-95.

http://dx.doi.org/10.1002/lt.20401

PMid: 15973720

20. Sundaram SS, Alonso EM, Anand R, et al. Outcomes after liver transplantation in young infants. Journal of Pediatric Gastroenterology and Nutrition 2008; 47(4): 486-92.

http://dx.doi.org/10.1097/MPG.0b013e318 $175 \mathrm{~d} 7 \mathrm{~d} 2$

PMid: 18852642 